Article

\title{
Holiday Hunger and Parental Stress: Evidence from North East England
}

\author{
Paul B. Stretesky ${ }^{1, *}$, Margaret Anne Defeyter ${ }^{2}{ }^{-}$, Michael A. Long $^{3}$, Liesel A. Ritchie ${ }^{3}$ and \\ Duane A. Gill ${ }^{3}$ \\ 1 Health Living Lab, Department of Social Sciences, Northumbria University, \\ Newcastle upon Tyne NE1 8ST, UK \\ 2 Healthy Living Lab, Department of Social Work, Education and Community Wellbeing, \\ Northumbria University, Newcastle upon Tyne NE7 7XA, UK; greta.defeyter@northumbria.ac.uk \\ 3 Department of Sociology, Oklahoma State University, Stillwater, OK 74078, USA; \\ michael.long@okstate.edu (M.A.L.); liesel.ritchie@okstate.edu (L.A.R.); duane.gill@okstate.edu (D.A.G.) \\ * Correspondence: Paul.Stretesky@Northumbria.ac.uk
}

Received: 22 April 2020; Accepted: 11 May 2020; Published: 19 May 2020

check for updates

\begin{abstract}
Summer is a stressful time of year for many parents as they struggle to meet household expenses and feed children. The aim of the present study is to determine if there is an association between summertime food insecurity (i.e., holiday hunger) and parental stress among a sample of UK parents with school age children living in North East England. A cross-sectional sample of $(n=252)$ parents are analyzed using holiday hunger as the independent variable and a subjective measure of stress that treats summer as a 'stressful event' as the dependent variable. Of the parents in the sample, $64.8 \%$ reported at least some level of holiday hunger. We find parents facing any holiday hunger scored substantively higher on the overall 75-point Impact of Event Scale (mean difference $=30.4$, 95\% confidence interval ((CI) 24.2-36.6), the 35-point intrusion subscale (13.7, 95\% CI 10.8-16.5), and the 40-point avoidance subscale (16.7, 95\% CI 13.3-20.2). These findings are replicated in a regression analysis. In addition, we find that holiday hunger partially mediates the association between economic hardship (i.e., unemployment and poverty) and parental stress. We conclude by suggesting that government policies addressing economic hardship are not only likely to reduce holiday hunger, but also improve mental wellbeing.
\end{abstract}

Keywords: seasonal food insecurity; parental wellbeing; mental health; summer childcare; family stress model

\section{Introduction}

Holiday hunger typically occurs in economically disadvantaged households with school-aged children and is characterized by food insecurity during the school holidays [1-3]. As the UK government considers how to alleviate holiday hunger, additional research is needed to help inform policy discussions. This research contributes to the ongoing policy dialog concerning holiday hunger by evaluating the association between holiday hunger and parental stress for a sample of parents of school aged children in North East England. Specifically, we draw upon the Family Stress Model (FSM) to hypothesize that economic hardship leads to holiday hunger which, in turn, is positively associated with (1) overall levels of parental stress; (2) intrusive thoughts about summer; and (3) avoidance behaviors. In addition, we suggest that holiday hunger will mediate the relationship between economic hardship and parental stress.

The remainder of this article is organized into four sections. In the first section we describe the Family Stress Model (FSM) to contextualize our empirical analysis of economic hardship, holiday 
hunger and parental stress. In particular, we explain why UK households with school aged children experience holiday hunger as a result of economic hardship [4]. That section also details how holiday hunger may lead to parental stress and presents five hypotheses based on the FSM model that will be investigated. The second section provides a brief overview of the analytic strategy used to examine our hypotheses and explains how we operationalize economic hardship, holiday hunger, parental stress. We propose that (1) holiday hunger can be measured using the 6 item United States Department of Agriculture (USDA) Household Food Security Survey Module [5] and (2) parental stress, including intrusive thoughts and avoidance behaviors, can be measured using the Impact of Event Scale [6]. The third section presents results from our univariate, bivariate and multivariate analyses. We not only find that holiday hunger is associated with stress, but that it partially mediates the relationship between economic hardship and stress. The fourth and final section concludes by offering some recommendations for future researchers and discusses the importance of our findings for holiday hunger policy in the UK.

\section{Theoretical Perspective}

The aim of this study is to assess the association between economic hardship (i.e., poverty and unemployment), holiday hunger and parental stress. We situate our investigation within the Family Stress Model (FSM) [7,8]. The FSM framework was developed by Conger and colleagues [9]. Above all, FSM helps explain how economic hardships drive childhood development. These hardships include low income and/or deleterious events such as a becoming unemployed or a situation such as living in poverty. In turn, hardships lead to household strain, such as the inability of parents to purchase enough safe foods to meet the dietary needs of their households. In short, household strain, such as the inability to be food secure can lead to deleterious mental health outcomes for parents. Parental stress often results in reductions in the quality and quantity of parenting practices including 'harsh' parenting practices which may adversely impact childhood development [9]. The presence or absence of various resources can intensify or attenuate the relationships between economic hardships and household pressures as well as the relationship between household pressures and parental stress [9]. As a result, it is not likely that there is a perfect association between economic hardship and household strain since not all unemployed parents and poor households are food insecure. The particular portion of the FSM model this study focuses on is slightly modified to accommodate the present investigation and is diagrammed in Figure 1 below [9] (p. 87).

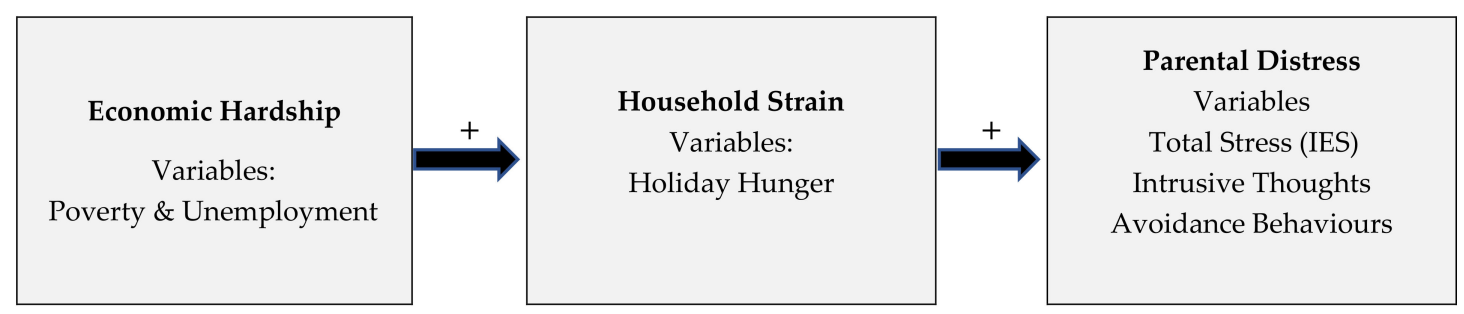

Figure 1. Diagram of Economic Hardship, Household Strain and Parental Stress.

In the remainder of this section we build additional theoretical support for the existence of an association between economic hardship, holiday hunger and parental stress. We begin by proposing that economic hardship leads to household strain in the form of holiday hunger. Next we suggest that holiday hunger gives way to parental stress about the summer-which we define as a stressful event. We conclude by proposing five hypotheses that summarize the relationship between economic hardship, holiday hunger and parental stress.

\subsection{Economic Hardship and Household Strain}

Unemployment is associated with devastating levels of economic hardship [10]. In the UK, unemployed residents are aided through welfare under a system of universal credit. This welfare 
system is meant to provide the unemployed with 'incentives' to find work by conditioning payments on activities such as applying for jobs. However, the ability of universal credit to attenuate economic hardship has been seriously questioned [11,12] and it appears universal credit has led to increased foodbank use [13]. Recent mental health studies also suggest that universal credit has produced serious psychological distress among those unemployed who use the system [14]. As a result, being unemployed in the UK means that basic needs, such as food security, are threatened [15]. Unfortunately, being employed does not always protect against economic hardship and there has also been an increase in 'in-work poverty' which leaves many households in a position where they are ineligible for benefits and unable to afford food [16]. Finally, currently studies suggest that gaining employment in the current market is also increasingly difficult for younger generations [17].

Poverty, which can be conceptualized as economic hardship that inhibits basic needs is also increasing in the UK. Atkinson [18] (p. 199) points out that the recent rise in UK poverty 'is among the largest of any Anglo-Saxon country.' Today, an estimated 19\% of all UK residents (or 12.5 million individuals) live in conditions of absolute poverty, meaning that after housing costs are considered today (in 2017/18) they resided in households that earned less than $60 \%$ of the median household income several years ago (in 2011/12) [19]. As a result, these 12.5 million residents are likely to experience a level of economic hardship that makes it difficult to meet their most basic needs, including accessing food. In sum, and consistent with the FSM model, unemployment and poverty are two of the strongest predictors of household food insecurity as household members may be hungry and often cannot consistently access enough healthy, nutritious and safe foods to meet their dietary needs [20-24].

\subsection{Household Strain and Parental Stress}

As a result of changing political economic conditions reviewed above, more UK households are becoming food insecure. As the FSM model predicts, food insecurity should have an impact on parents [25]. In particular, within food insecure households, the mental health of parents is attracting increased attention [26,27]. For instance, Gee and Asim [26] found that USA parents who became food insecure as a result of the Great Recession (2007 to 2009) reported a subsequent increase in parental aggravation. Those parents were more likely than parents who did not become food insecure to say that (1) parenting was harder than they thought, (2) that their child did things that bothered them, (3) they gave up their life to meet their child's needs, and (4) they were angry at their child. Moreover, studies of parents and caregivers suggest that parents who are living in food insecure households believe they are 'inadequate' or 'failures' [26]. Other studies suggest that parents who are food insecure are more likely to be diagnosed with stress, anxiety and depression [27-29]. Finally, research on food insecurity and parents' mental health also suggests that stress varies by gender. Female parents are more likely than male parents to feel anxious and depressed in response to levels of food insecurity in their households [27-29]. In addition to the likely relationship between food insecurity and mental health more generally, we suggested that food insecurity can lead to psychological distress.

\subsection{Holiday Hunger}

There are two reasons that holiday hunger is likely to have a substantive impact on parental stress. First, schools (typically through government supported programs) provide free school meals to children from low-income families to help them meet dietary requirements during the school year and not during the school holidays. This situation means that some UK households move in and out of food security as seasons change. The summer school holiday is one of the longest school breaks of the year where households are forced to forgo free meals. Many low-income working parents say that school holidays are a significant strain on their household because they must pay for childcare. As a seasonal event, holiday hunger produces an emotional strain on parents who must find alternative ways to feed their children when they are not in school [30-32]. In addition, childcare costs often compete directly with household food budgets $[30,33]$. In short, some parents report that school holidays are different from other times of the year. 
Second, school holidays are often described as traumatic or an impactful event in their lives of parents because their households are struggling financially [3,34,35]. Currently, most studies of holiday hunger are focused on the overall wellbeing of children [36-38] and few examine how parents' health and wellbeing are impacted (except see [30,39]). In the UK, qualitative research suggests that holiday hunger may impact parental stress. Parents in poverty say that they see summertime as an impending event and are aware that they will be unable to meet the financial needs of their household, including feeding their children $[30,33,40]$. Moreover, low-income parents often suggest that during the summer they struggle to pay for childcare, cannot provide children with entertainment, may have to skip payment for utilities, struggle to feed all the members of the household (with parents themselves often saying they skip meals to feed their children), and cannot buy school uniforms [30]. While economically disadvantaged parents have developed coping strategies to mitigate these financial strains, what is clear is that many parents view the summer as a stressful event that they constantly think about (i.e., have intrusive thoughts about) or try to ignore (i.e., avoid for as long as possible). As a result, it is likely that the economic hardship leads to household strain that generates parental distress. While food insecurity and mental health have been examined in general using the FSM framework, we are aware of no studies that have examined summertime as a stressful event for parents using that framework. Nevertheless, the FSM framework and observations about holiday hunger and parental stress lead us to the following five hypotheses:

Hypothesis 1 (H1). Economic Hardship is positively associated with holiday hunger. As a result, as poverty and unemployment increase, holiday hunger will also increase across the sample of parents.

Hypothesis 2 (H2). Holiday hunger is positively associated with overall levels of parental stress. Thus, as holiday hunger increases, summer stress will also increase across the sample of parents.

Hypothesis 3 (H3). Holiday hunger is positively associated with intrusive thoughts about summer stress. Therefore, as holiday hunger increases, intrusive thoughts will also increase across the sample of parents.

Hypothesis 4 (H4). Holiday hunger is positively associated with avoidance behaviors. Therefore, as holiday hunger increases, avoidance behaviors will also increase across the sample of parents.

Hypothesis 5 (H5). Holiday hunger will mediate the relationship between economic hardship and parental stress in the case of (1) overall levels of stress, (2) intrusive thoughts and (3) avoidance behaviours.

Each of these hypotheses is consistent with the FSM framework and extends that framework beyond an examination of overall tests of food insecurity and mental health to consider summer as a particular stressful event that results from holiday hunger.

\section{Data and Methods}

To examine the association between holiday hunger and parental stress we rely on a cross-sectional survey of parents in two local authorities in North East England. Data were gathered in August 2019 (toward the end of the school holiday) with the help of local authorities using an electronic questionnaire distributed to a sample of 640 parents of children and young people facing various levels of economic hardship (return rate $=39 \%$ ). Importantly, for the purposes of this research, the economic status of the parents we examine are likely to range from low- to high-income and therefore include parents who are facing economic hardship. To obtain the sample, parents were contacted by the local authorities by email, or in person, and asked to take the survey if they resided within the local authority areas, and had at least one child 16 years old or younger who attended at least one recently run (or funded) local authority summer activity. Data were imported into Stata ver. 14 (StataCorp, College Station, TX, USA) and analyzed using Ordinary Least Squares (OLS) regression so that the relationship 
between economic hardship, holiday hunger and summer stress could be evaluated in relation to our five hypotheses.

\subsection{Sample Characteristics}

The characteristics of the $n=252$ parents included in the sample are presented in Table 1 below. Ethical approval for the questionnaire was granted by Northumbria University. Parents who took part in the survey provided informed consent electronically and the researchers were not provided with any data that could be used to uniquely identify any participants.

Table 1. Characteristics of the Sample and Population.

\begin{tabular}{ccc}
\hline Characteristic & Sample & Population \\
\hline \% Unemployed & 29 & 5.5 \\
\% Separated or Divorced & 18.2 & 8.2 \\
\% Married & 36.6 & 40.6 \\
\% Female & 83.3 & 51 \\
Median Age & $36-45$ & 37 \\
\hline
\end{tabular}

Notes: $n=252$; Population data represent weighted averages across the two local authorities for the 2011 Census and were obtained from the UK's Office of National Statistics at https://www.ons.gov.uk/census/2011census/ 2011censusdata/2011censusdatacatalogue.

Table 1 presents a typical picture of what might be expected from the given the sampling frame. First, median age of the sample (i.e., 36 to 45 years old) is relatively similar to the median age of in the local authority population (e.g., 37). Moreover, roughly the same percentage of parents are married in the sample as are married in the population (36.6\% vs. $40.6 \%)$. There is, however, a significantly higher proportion of females in the sample than in the population ( $83.3 \%$ vs. $51 \%)$. This finding is not surprising and reflects the fact that women are more likely than men to arrange childcare and childcare activities [41]. Thus, most of the email addresses in the sampling frame likely belonged to women as opposed to men. In addition, unemployment rates among the sample are greater than the unemployment rates in the population ( $29 \%$ vs. $5.5 \%$ ). Again, this is not unusual given that some programs run by councils (e.g., holiday clubs) are focused on households facing poverty or other economic hardships. The data on the percentage of parents who report that they are divorced or separated is much higher in the sample than in the population ( $18.2 \%$ vs. $8.2 \%)$. Thus, while the sample is hardly completely representative of the population, it includes enough of the types of participants needed to examine the relationship between holiday hunger and parental summertime stress. That is, the sample includes a sufficient number of households impacted by economic hardship. The sample provides a unique opportunity to examine the relationship between holiday hunger and parental stress across the entire spectrum of economic hardship.

\subsection{Parental Stress}

We measure the dependent variable, parental stress, using the Impact of Event Scale (IES). The IES was developed by Horowitz et al. [6] and uses 15 questions to measure the subjective stress people face in response to serious life events. The IES has been used to study events such as injuries, sickness and cancer, job pressures, various human rights violations and environmental disasters [42-46]. Participants were asked to read the following statement prior to answering the 15 questions:

Some people report that school summer holidays are more stressful than other times of the year because of extra financial obligations, limited access to food, increased caregiver responsibilities and/or added constraints on time. The statements below are made by people after they experience stressful life events. For each statement, please indicate how often this was true for you when thinking about the school summer holiday as a stressful time during the past seven days. 
Responses to each statement are coded as " 0 " = not at all, " 1 " = rarely, " 3 " = sometimes, and " 5 " $=$ often and then added together to create an overall subjective measure of psychological stress that ranges from 0 (no impact) to 75 (severe distress).

The IES also includes an overall stress score and subscale scores for intrusion and avoidance. The intrusion subscale measures those thoughts that cause people to think about or re-experience traumatic events and includes things such as nightmares and imagery of the event. In the present study the intrusion scale is measured by 7 of the 15 IES items that ask how much parents would allow the hardship of summertime to enter into their thoughts (i.e., "I thought about it when I didn't mean to," "Any reminders brought back feelings about it", "I had trouble staying asleep", "pictures about it popped into my mind", "I found myself acting or feeling like I was back at that time," "I had waves of strong feelings about it," and "I had dreams about it"). The Intrusion subscale is internally consistent (e.g., Cronbach's $\alpha=0.96$ ) and we expect it will be related to food insecurity in a way that is similar to overall levels of parental summer stress. The avoidance subscale measures the averting of situations, ideas and feelings that bring back thoughts of the event (i.e., "I avoided letting myself get upset when I thought about it or was reminded about it", "I felt as if it didn't happen or was not real", "My feelings were kind of numb", "I tried to remove it from my memory", "I was aware that I still had a lot of feelings about it, but I didn't deal with them," "I avoided reminders of it," "I tried not to think of it", "I tried not to talk about it"). The Avoidance subscale consists of 8 of the 15 IES items and also obtained a high internal consistency score (Cronbach's $\alpha=0.98$ ) and we believe it will be related to food insecurity in a way that is similar to overall levels of parental stress.

\subsection{Holiday Hunger}

Our main independent variable of interest that measures economic pressure is holiday hunger. We measured holiday hunger using a slightly modified version of the USDA's household food security scale [5]. The questions used to construct the scale include (1) "During the summer holidays, food that we bought just didn't last, and we didn't have money to get more." (2) "During the summer holidays we couldn't afford to eat balanced meals." (3) "During the summer holidays did you or other adults in your household ever cut the size of your meals or skip meals because there wasn't enough money for food." (4) "You ate less than you felt you should during the summer holidays because there wasn't enough money for food," and (5) "You were hungry during the summer holidays but didn't eat because there wasn't enough money for food." These questions were developed specifically to measure food insecurity in households and have been empirically tested and verified across a number of studies $[47,48]$. The answers to these questions were coded set " 0 " $=$ never, " 1 " = sometimes and " $2 "$ = often. Food insecurity scores range from 0 (no food insecurity) to 10 (high food insecurity). Cronbach's $\alpha$ for the holiday hunger scale is 0.96 , suggesting high internal consistency for this variable.

\subsection{Economic Hardship}

The FSM framework suggests that economic hardship is an important predictor of household strain. We account for hardship by looking at unemployment and poverty as they have been used in the FSM framework as predictors of parental stress. We use a dichotomous variable to measure unemployment (" 1 " = unemployed and " 0 " = employed part time of full time). As previously noted, we hypothesized those unemployed parents are more likely to experience economic hardship that can lead to holiday hunger and parental stress [7]. Next, we measure poverty (" 1 " = poverty " 0 " = not in poverty) through a proxy measure that establishes whether members of the household used any local authority funded services where attendance was restricted based on financial need (e.g., children who attended an event had to be eligible for free school meals). As suggested, we anticipate that poverty status is positively related to holiday hunger and parental stress. 


\subsection{Additional Control Variables}

We account for other variables that might impact the association between holiday hunger and parental stress. First, we account for childcare costs as an additional measure of household strain. We measure childcare costs in hundreds of pounds sterling $€$. Childcare costs over the summer are often viewed as a significant source of stress for parents and could elevates levels of parental stress [30]. In addition to adjusting for the influence of childcare costs we also explore the potential influence of gender, number of children in a household, relationship status and age. First, the gender of survey participants (coded " 1 " = female and " 0 " = not female) has been found to be important in predicting levels of stress. As previously noted, the mental health outcomes of household strain are gender based and more likely to negatively impact the mental health outcomes, and possibly stress, among mothers as opposed to fathers [49]. Second, because the number of children in a household may increase financial pressure, we also control for the number of children 16 and under living in the household. We suggest that more children should be related to higher levels of parental stress during the summertime because there are more household members to feed. Finally, we adjust for both relationship status and parental age. We suggest younger parents and single parents who are single, divorced or separated are more likely to feel the pressure of holiday hunger as they have less household support [50]. Relationship status is dichotomous and coded " 1 " $=$ single parent and " 0 " = not single. Age was measured ordinally, with the age range of parents and other caregivers measured in ten-year categories scored " 1 " to " 5 " (i.e., " 1 " = 19-25, "2" = 26-35, " 3 " = 36-45, " 4 " = $45-55$ and " 5 " = 56 and older). Basic descriptive statistics and bivariate correlations for all variables in this study are included in Table A1 of Appendix A to allow for the replication of findings.

\subsection{Analytic Strategy}

Theoretically, we are interested in the FSM framework and its application to holiday hunger. In particular, we examine the association between economic hardship, holiday hunger and parental stress while adjusting for control variables. To build support for our models we first examine the variables holiday hunger and parental stress to establish that there is sufficient variation for analyses. Next, we examine the bivariate association between holiday hunger and parental stress by using an independent sample t-test. In particular we compare mean parental stress scores for those parents who (1) report that they are food secure and (2) those that report they face some level of food insecurity. Finally, we estimate a series of OLS regression coefficients to test our five hypotheses. OLS is an appropriate statistical technique in the present study as it allows us to simultaneously examine the association of multiple independent variables on one continuous dependent variable [51].

We follow the analytic strategy recommended by Baron and Kenny [52]. First, holiday hunger is regressed on economic hardship (poverty and unemployment) and control variables; second, parental stress (total, intrusive thoughts, and avoidance behaviors) is regressed on economic hardship and controls; and third, parental stress (total, intrusive thoughts and avoidance behaviors) is regressed on economic hardship, holiday hunger and controls. If holiday hunger mediates the relationship between economic hardship and parental stress, then four conditions will be observed. First, there will be an association between household strain and holiday hunger. Second, there will be an association between economic hardship (poverty and unemployment) and parental stress. Third, there will be a relationship between holiday hunger and parental stress. Finally, the effect of economic hardship (poverty and unemployment) must be less when holiday hunger is controlled than when holiday hunger is not controlled. If the effect of economic hardship on parental stress becomes statistically insignificant when holiday hunger is controlled, then holiday hunger completely mediates the relationship between economic hardship and summer stress.

When conducting the multivariate analyses, we examined the residuals for potential problems that might lead to incorrect conclusions about the relationship between holiday hunger and parental stress [51]. First, a visual inspection of the residuals suggests that they are normally distributed and the largest skewness (-0.76) and kurtosis (1.5) scores for any models estimated were well within acceptable 
ranges for a normal distribution. Moreover, there do not appear to be any outliers in our model that introduce undue influence on the coefficients we estimate. Finally, the variance of the model residuals appears to be relatively constant across all values of the independent variables and are homoscedastic in nature.

Given that several independent variables in this study measure some aspect of economic hardship, it is possible that multicollinearity presents a problem in the OLS models that we estimate. Multicollinearity may cause instability in model estimates leading to uncertainty about results. To establish if multicollinearity may be a problem in the models estimated we first examine all bivariate correlations among the independent variables (Appendix A). Correlations among independent variables were weak to moderate (i.e., $|r|<0.50$ ). However, the relationship between poverty and holiday hunger was 0.46 . This correlation does not appear to be strong enough to introduce multicollinearity into any models estimated. However, bivariate intercorrelations among independent variables are not necessarily indicative of problematic multicollinearity. Thus, we also examine variance inflation factor (VIF) scores for each variable in the regression models to see if the combined correlations may be harmful, noting that VIF scores between 4 and 10 (or larger) may constitute evidence of harmful collinearity [53]. None of the models produced a variable with a VIF score that exceeded 1.7, with the highest VIF score of 1.67 for full time employment. In addition, the average VIF score is 1.3 in the full model. Thus, VIF scores combined with evidence of low to moderate correlations among independent variables and the overall stability of estimates across statistical models presented in the findings suggests that multicollinearity is not a problem for these data. Statistically, these models appear to be appropriate for summarizing the relationship between holiday hunger and parental summer stress. To help with hypotheses testing we employ the Akaike information criterion (AIC), a post-estimation statistic, to identify the best fitting models [54].

\section{Findings}

As previously noted, findings are separated into three sections. First, we examine the distribution of parental stress (total stress, intrusion and avoidance) and holiday hunger in the sample. Next, we examine the bivariate relationship between holiday hunger and parental stress to see if there is initial support for hypotheses 2 to 4 . Finally, we produce a series of regression models to examine hypotheses 1 to 5 in more detail as explained in the analytic strategy while controlling for other variables that may be related to holiday hunger and parental stress.

\subsection{Distribution of Parental Stress and Holiday Hunger}

We suggested that summertime is viewed by many parents as a stressful event that can be measured by the IES and its avoidance and intrusion subscales. Table 2 displays a frequency distribution for the overall parental stress scores. In order to provide a sense of how much impact summer stress may have on parents, these IES scores are grouped into those that indicate summer had "no meaningful impact" to those that indicate summer had "a severe impact." These categories are used by researchers who employ the IES to identify stressful events [55].

Table 2. Distribution of Parent Stress by Impact of Event Category.

\begin{tabular}{ccc}
\hline Summer Had & Frequency $(f)$ & Percent (\%) \\
\hline No Meaningful Impact (0 to 10 points) & 82 & 32.5 \\
An Impact (10 to 25 points) & 32 & 12.7 \\
A Powerful Impact (26 to 44 points) & 20 & 7.9 \\
A Severe Impact (45 to 71 points) & 81 & 32.1 \\
Missing Cases & 37 & 14.7 \\
$n$ & 252 & \\
\hline
\end{tabular}


Table 2 provides evidence that summer is viewed as a significant negative psychological event for a significant percentage of parents in our sample. While the most common response by parents is that summertime did not cause any psychological stress (i.e., $32.5 \%$ ) a nearly equal percentage reported that it caused severe stress (i.e., $32.1 \%$ ). This variation in parental stress scores is important for examining overall stress scores as an outcome measure in regression as the full range of possible IES scores are used by parents. While parental stress is not normally distributed, it can serve as dependent variable in a regression analysis because the model residuals are normally distributed in each model we estimate in the multivariate analysis.

Figure 2 shows the distribution of the intrusion and avoidance subscales. Both intrusion and avoidance also appear to be distributed across the full range of potential scores (i.e., ' 0 ' to ' $35^{\prime}$ ' for intrusion and ' 0 ' to ' 40 ' for avoidance). Both distributions have similar shapes, though a higher frequency of parents in this particular sample appear to report at least some level of intrusive thoughts when it comes to holiday hunger than engage in some level of avoidance behaviors. As previously noted, many parents rely on year around coping strategies to deal with holiday hunger. Thus, it may be that they are unable to also employ avoidance type behaviors to deal with the stress that comes with summer. Whatever the reason for less frequent reports of avoidance behaviors than intrusive thoughts, it is clear that at least some parents experience both types of stress responses and that the entire range of each subscale is represented in these parents.

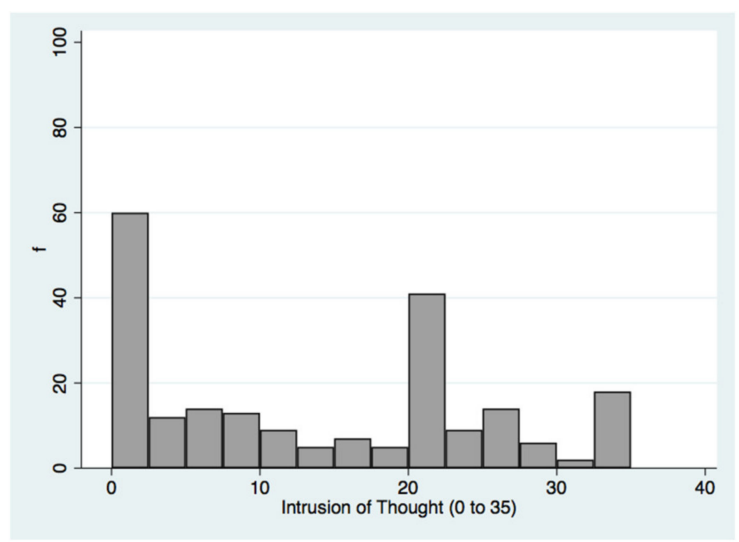

(a)

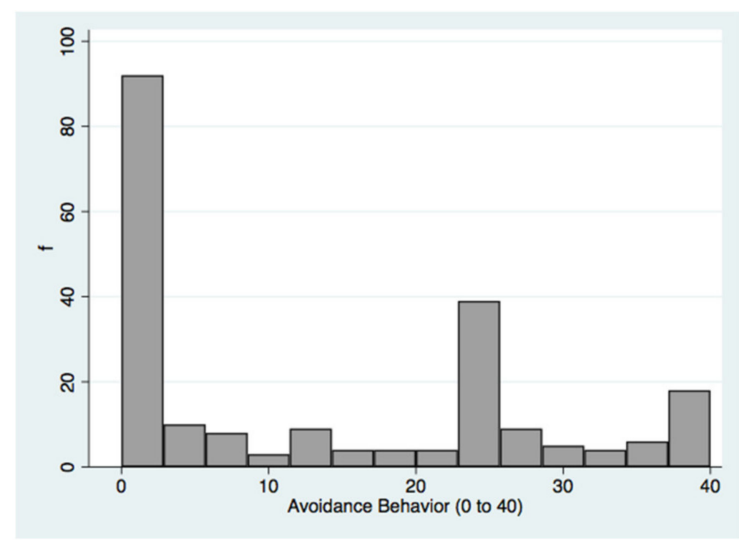

(b)

Figure 2. Histogram of Parents' Intrusion of Thought (a) and Avoidance Behavior (b).

As previously noted, parents choose one of three answers for each of the five holiday hunger items. These items were coded " 0 " to" 2 ", suggesting that when items were added together the holiday hunger index could range from 0 (no holiday hunger) to 10 (highest level of holiday hunger). The histogram of holiday hunger scores is displayed in Figure 3.

As demonstrated in Figure 3, the most common response by parents $(n=83)$ is " 0 ", suggesting their households are food secure and therefore do not experience holiday hunger. However, $n=48$ parents reported their households faced moderate levels of holiday hunger (i.e., a score of " 5 ", or an average of 1 point on each of the 5 items). Finally, $n=32$ parents reported that their households often face holiday hunger by responding often (a score of " 2 ") to each of the ten items on the scale. Other responses fell in-between these index scores and represented a mixture of responses on items that ranged from "never" to "sometimes" to "often" for each of the holiday hunger items. Importantly, a significant percentage of households in the sample experience holiday hunger and the range of responses for the variable include the entire scale. Finally, the variable holiday hunger is not normally distributed. As previously noted, this non-normality does not impact the multivariate regression since it is the residuals that must be normally distributed to fulfill statistical assumptions. 


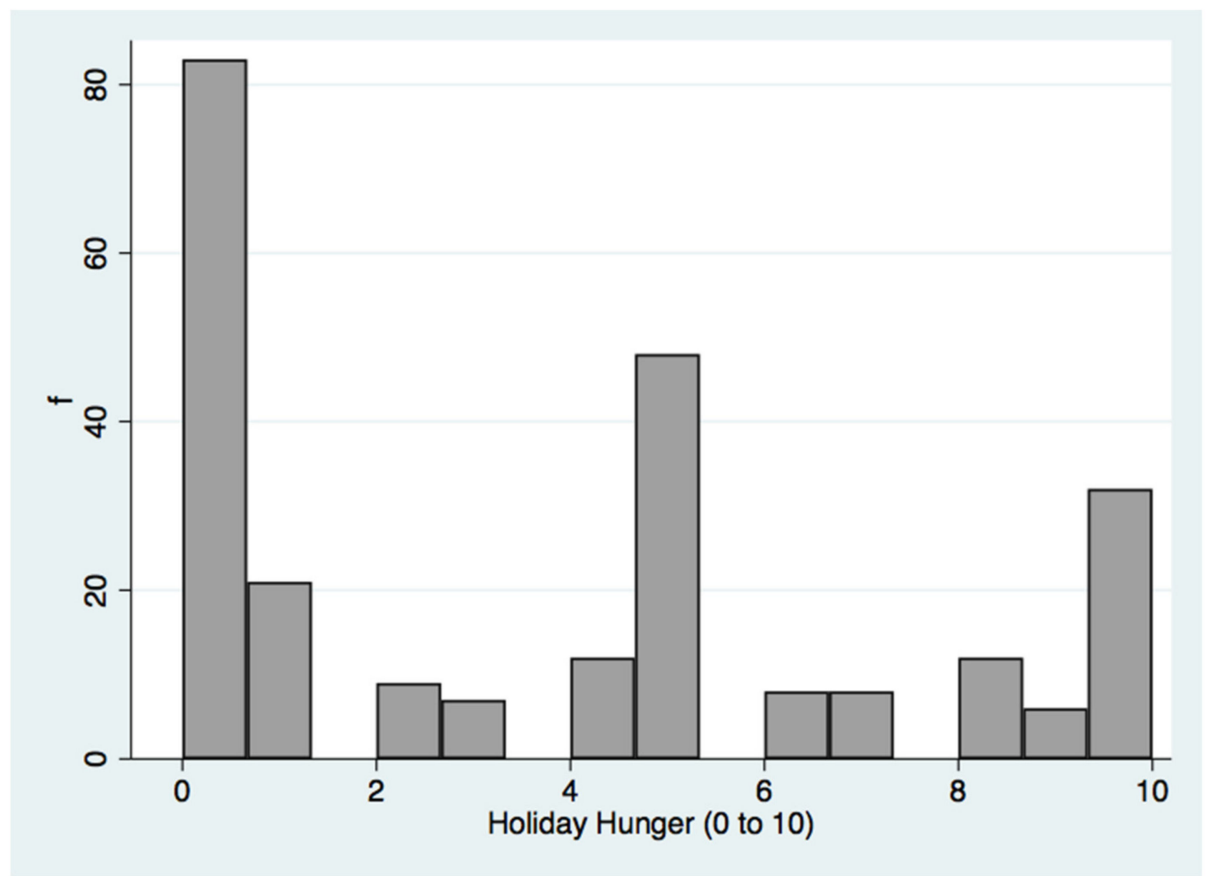

Figure 3. Histogram of Holiday Hunger in Parent Households.

\subsection{Bivariate Relationship Parental Stress and Holiday Hunger}

We next analyze the mean difference in parental stress scores for two groups of parents: (1) those parents that report that they face no food insecurity during the summer holidays (i.e., Holiday Hunger $=" 0$ ") and (2) those parents that report they face at least some food insecurity during the summer (i.e., Holiday Hunger $>$ " 0 "). We examine these differences by comparing means for independent samples (Table 3). Table 3 reports the results of this comparison of means by presenting the mean of Total Stress, Intrusion and Avoidance for the two groups of parents described above. We include the difference in means between these two samples and the $95 \%$ confidence intervals built around those means.

Table 3. Comparison Holiday Hunger and non-Holiday Hunger Households Using a Difference of Means Test(a,b).

\begin{tabular}{ccccc}
\hline Variable & Holiday Hunger $=\mathbf{0}$ & Holiday Hunger $>\mathbf{0}$ & Difference & SE Difference (95\% CI) \\
\hline Total Stress & 5.72 & 36.11 & 30.38 & $3.14(24.20,36.57)^{*}$ \\
Intrusion & 4.02 & 17.67 & 13.65 & $1.45(10.81,16.51)^{*}$ \\
Avoidance & 1.71 & 18.43 & 16.72 & $1.16(13.27,20.18)^{*}$ \\
$n$ & 65 & 150 & & \\
\hline
\end{tabular}

Notes: ${ }^{*} p<0.05$; Missing data on 37 parents; A Mann -Whitney $U$ non-parametric test for identical distributions confirms findings for Total Stress, Intrusion and Avoidance ( $p<0.05$ for each test).

Results in Table 3 suggest that parents who reported that they faced no holiday hunger scored on average of 5.72 on the Parental Stress Variable, 4.02 on the Intrusion variable and 1.71 on the Avoidance variable indicating that these parents did not experience stress, including intrusive thoughts or engage in avoidance behaviors for the 15 items. In contrast, those who noted that they experienced some levels of holiday hunger scored an average of 30.38 on the Parental Stress Variable, including 17.67 on the intrusion variable and 18.43 on the avoidance behaviors variable. This indicates that, on average, Holiday Hunger had a 'Powerful Impact' on parents' perceptions of summer as a traumatic event. This difference of 30.38 is statistically significant $(p<0.05)$ and could be as low as 24.20 or as high as 36.57 in the population. The results in Table 3 also show that the differences in average Intrusion and Avoidance scores for the two groups of parents are also statistically significant. In particular, the difference in parental stress for intrusion was 13.65 (95\% CI 10.81-16.51) and for avoidance was 
16.72 (95\% CI 13.27-20.18). These findings suggest, at least at the bivariate level, hypotheses 2 to 4 (that holiday hunger is positively related to parental stress) is supported. Because parental stress was not normally distributed, we also use the non-parametric Mann-Whitney $U$ test that confirms the results in Table 3 (results not shown).

\subsection{Multivariate Analyses of Parental Stress and Holiday Hunger}

While the bivariate results presented in Table 3 suggest a relationship between holiday hunger and parental stress, those results do not investigate the role of economic hardship and holiday hunger or the impact of holiday hunger on parental stress while accounting for other parent and household factors. Thus, to explore our hypotheses in more detail we follow the analytic procedure described in Section 3.5. We estimate unstandardized regression coefficients along with the $95 \%$ confidence intervals built around those estimates in Tables 4-6. The $R^{2}$ is included for each model and summarizes the overall goodness of fit and the AIC is included to compare models with different sets of independent variables to ensure a robust test of our hypotheses by considering potential over and under fit models.

We begin our multivariate analysis by regressing holiday hunger on Unemployment, Poverty and controls (Model 1, Table 4) to establish that economic hardship is positively associated with Holiday Hunger as is suggested by the FSM framework.

Table 4. Regression of Holiday Hunger on Economic Hardship (Poverty and Unemployment) and Controls.

\begin{tabular}{ccc}
\hline Variables & Model 1 & Coeficient $(95 \%$ Confidence Interval) \\
\hline Unemployed & 1.32 & $(0.33,2.308)^{* *}$ \\
Poverty & 1.98 & $(1.03,2.936)^{* *}$ \\
Childcare Costs & -0.19 & $(-0.7,0.324)$ \\
Female & -0.21 & $(-1.46,1.04)$ \\
No. Children & 0.41 & $(-0.07,0.903)$ \\
Age of Parent & 0.02 & $(-0.56,0.605)$ \\
Single Parent & 2.52 & $(1.53,3.508)^{*}$ \\
Constant & 0.79 & $(-1.96,3.56)$ \\
$n$ & 175 & \\
$\mathrm{R}^{2}$ & 0.32 & \\
AIC & 5.08 & \\
& Notes: ${ }^{* *} p<0.05 ;{ }^{*} p<0.10$.
\end{tabular}

As Table 4 suggests, parents who are unemployed report higher levels of holiday hunger than parents who are employed full time. In particular, across the sample, unemployed parents score an average of 1.32 points higher $(95 \%$ CI $0.33-2.31)$ on the 10-point holiday hunger scale than parents who are employed. The same situation holds true for estimated poverty status. That is, parents living in poor households are estimated to score an average of 1.98 points higher on the on the 10-point holiday hunger scale than parents in households that are not in poverty. The estimated model in Table 4 explains nearly 32 percent of the variance in holiday hunger and alternative models do not substantively improve the model (lowest alternative AIC $=5.01$ ) and do little to change the coefficients for poverty and unemployment (results not shown). In short, there is substantial evidence that economic hardship, as measured by poverty and unemployment, increases holiday hunger. This finding provides considerable support for Hypothesis 1 and the notion that economic hardship leads to holiday hunger. In addition to the impact of poverty and unemployment on holiday hunger we also find that single parent households have a large impact on food insecurity. In particular, parents living in a single-family household score an average of 2.52 points higher on the 10-point holiday hunger scale than parents who are not in single parent household.

Table 5 examines parental stress by regressing it on two measures of economic hardship (Poverty and Unemployed) and controls (Models 2-4). As Table 5 suggests, parents who live in households in poverty report higher levels of summer stress (21.0, 95\% CI 14.7-27.4), higher levels of intrusive 
thoughts (9.2, 95\% CI 6.2-12.2) and higher levels of avoidance behavior (11.9, 95\% CI 8.4-15.4). Moreover, the impact of poverty is substantial since being in poverty is associated with an average increase of 21.0 points in total parental stress (Model 1, Table 5). This increase in the IES score is easily large enough to differentiate between a parent who is 'not impacted' or is 'powerfully impacted' by summertime. We also find that unemployment is only marginally significant $(p<0.10)$ to parental stress in Models 2 and Models 4 (Table 5). Unemployment is unrelated to summertime stress in Model 3 in the case of intrusion. This finding for unemployment is somewhat surprising as we theorized that it is an economic hardship that is likely to cause, indirectly at least, significant parental stress. To explore this issue in more detail we estimated the best fitting model (AIC $=8.81$ ) with unemployment in the model and re-examined the relationship between unemployment and parental stress. In that case the association continues to remain statistically insignificant $(4.4,95 \%$ CI 1.7-10.4). It is only when Poverty is excluded from the model that Unemployed is statistically significant (6.8, 95\% CI 0.0-13.6). Without poverty in the model however, it is comparatively worse and appears to underfit these data (AIC $=9.1$. . Repeating this procedure for intrusion and avoidance produces similar results (not shown). In short, poverty is substantively significant, and unemployment has a marginally significant impact, at best, on overall parental stress, intrusive thoughts and avoidance behaviors.

Table 5. Regression of Parental Stress on Financial Hardship (Unemployment and Poverty) and Controls.

\begin{tabular}{|c|c|c|c|}
\hline Variables & $\begin{array}{l}\text { Model } 2 \text { (Total Stress) } \\
\text { Coeficient ( } 95 \% \text { CI) }\end{array}$ & $\begin{array}{l}\text { Model } 3 \text { (Intrusion) } \\
\text { Coeficient }(95 \% \text { CI) }\end{array}$ & $\begin{array}{l}\text { Model } 4 \text { (Avoidance) } \\
\text { Coeficient (95\% CI) }\end{array}$ \\
\hline Unemployed & $5.86(-0.70,12.4)$ * & $2.28(-0.81,5.37)$ & $3.58(-0.03,7.18)$ * \\
\hline Poverty & $21.05(14.70,27.40)^{* *}$ & $9.17(6.18,12.17)^{* *}$ & $11.88(8.39,15.37)^{* *}$ \\
\hline Childcare Costs & $2.16(-1.21,5.54)$ & $1.09(-0.51,2.68)$ & $1.08(-0.78,2.94)$ \\
\hline Female & $-3.03(-11.31,5.24)$ & $-0.56(-4.46,3.34)$ & $-2.47(-7.02,2.07)$ \\
\hline No. Children & $3.22(-0.06,6.50)$ * & $1.52(-0.03,3.07)$ * & $1.70(-0.11,3.50)$ * \\
\hline Age of Parent & $-0.61(-4.46,3.23)$ & $-0.61(-2.42,1.20)$ & $0.00(-2.12,2.11)$ \\
\hline Single Parent & $15.01(8.44,21.58)^{* *}$ & $6.08(2.98,9.18)^{* *}$ & $8.92(5.31,12.54)^{* *}$ \\
\hline Constant & $5.01(-13.29,23.30)$ & $0.29(-4.02,13.23)$ & $0.40(-9.66,10.46)$ \\
\hline$n$ & 185 & 185 & 185 \\
\hline $\mathrm{R}^{2}$ & 0.41 & 0.37 & 0.43 \\
\hline AIC & 8.86 & 7.35 & 7.66 \\
\hline
\end{tabular}

There are two other variables that stand out as important. First, the number of children in the household is marginally significant $(p<0.10)$ and each additional child raises total IES scores by 3.2 points, intrusive thoughts by 1.5 points and avoidance behaviors by 1.7 points across the sample. These results, while marginally significant, are not substantively important compared to the effect of living in poverty which has seven to eight times the impact on parental stress across the models in Table 5 as adding one child to a household. We also find that being a single parent appears to matter. That is, single parents have parental stress scores that are 15 points higher (95\% CI, 8.4-21.6) on average than non-single parents. This association exists for intrusive thoughts $(6.1 ; 95 \%$ CI 3.0-9.2), and avoidance behaviors (8.9, 95\% CI 5.3-12.5). While the estimated impact of being a single parent does not reach the potential impact of poverty, it is substantial, nonetheless. None of the other variables in the model are statistically significant.

Table 6 examines the potential impact of economic hardship and holiday hunger on overall levels of parental stress (Model 5), intrusive thoughts (Model 6) and avoidance behavior (Model 7). As those models suggests, holiday hunger is related to total stress (4.26, 95\% CI 3.49-5.02), higher levels of intrusive thoughts (1.91, 95\% CI 1.53-2.28) and avoidance behavior (2.35, 95\% CI 1.93-2.77). The substantive significance of holiday hunger is significant. For instance, according to Model 4 (Table 6) a parent scoring 10 on the holiday hunger scale (see Figure 2) is predicted to score 42.6 points more on the IES than a parent scoring 0 on the holiday hunger scale. This increase alone is large enough to differentiate between a parent who is "not impacted" and one who is "severely impacted"by 
summer distress. This impact is repeated for Model 6 (i.e., an increase of 19.1 points) and Model 7 (an increase of 23.5 points). Moreover, these findings replicate the bivariate results (Table 3) while controlling for economic hardship and other parent and household characteristics. Finally, the results concerning holiday hunger support Hypotheses 2-4. That is, holiday hunger is positively related with parental stress, intrusive thoughts and avoidance behavior.

Table 6. Regression of Parental Stress on Holiday Hunger, Financial Hardship (Unemployment and Poverty) and Controls.

\begin{tabular}{cccc}
\hline Variables & $\begin{array}{c}\text { Model 5 (Total Stress) } \\
\text { Coeficient } \mathbf{9 5 \%} \text { CI) }\end{array}$ & $\begin{array}{c}\text { Model 6 (Intrusion) } \\
\text { Coeficient (95\% CI) }\end{array}$ & $\begin{array}{c}\text { Model 7 (Avoidance) } \\
\text { Coeficient (95\% CI) }\end{array}$ \\
\hline Holiday Hunger & $4.26(3.49,5.02)^{* *}$ & $1.91(1.53,2.28)^{* *}$ & $2.35(1.93,2.77)^{* *}$ \\
Unemployed & $-0.15(-5.33,5.02)$ & $-0.42(-2.93,2.10)$ & $0.26(-2.58,3.11)$ \\
Poverty & $12.02(6.85,17.18)^{* *}$ & $5.12(2.60,7.63)^{* *}$ & $6.90(4.06,9.73)^{* *}$ \\
Childcare Costs & $2.88(0.27,5.49)^{* *}$ & $1.41(0.14,2.68)^{* *}$ & $1.47(0.04,2.91)^{* *}$ \\
Female & $-2.03(-8.42,4.36)$ & $-0.11(-3.22,3.00)$ & $-1.92(-5.43,1.59)$ \\
No. Children & $1.65(-0.90,4.20)^{*}$ & $0.82(-0.42,2.06)^{*}$ & $0.83(-0.57,2.23)^{*}$ \\
Age of Parent & $-0.81(-3.78,2.16)$ & $-0.70(-2.14,0.75)$ & $0.11(-1.74,1.52)$ \\
Single Parent & $4.62(-0.79,10.03)^{*}$ & $1.42(-1.21,4.05)$ & $3.20(0.23,6.17)^{* *}$ \\
Constant & $1.93(-13.29,23.30)$ & $3.22(-3.66,10.10)$ & $-1.29(-9.06,6.47)$ \\
$n$ & 185 & 185 & 185 \\
$R^{2}$ & 0.65 & 0.60 & 0.66 \\
AIC & 8.35 & 6.9 & 7.14 \\
\hline
\end{tabular}

Notes: ${ }^{*} p<0.10 ;{ }^{* *} p<0.05$

Turning to Hypothesis 5, we find some support for the idea that holiday hunger mediates the relationship between economic hardship and total stress, intrusive thoughts and avoidance behaviors. In particular, unemployment is no longer marginally significant in Models 5 to 7 (Table 6). Moreover, when holiday hunger is included in any tested model, unemployment is not statistically significant (results not shown). Additionally, the unstandardized coefficients for poverty are now nearly one-half of what they were in Table 6. For instance, in Table 5 the coefficient for poverty is 21.05 and in Table 6 it is 12.02 (95\% CI 6.85-17.18). The finding in Table 6 suggests that while poverty still has a direct effect on all types of parental stress, holiday hunger partially mediates the relationship between this measure of financial strain and parental stress. Moreover, the AIC suggests an improvement in the model specification in Table 6 when holiday hunger is included in Models 5 to 7 (when compared to Models 2 to 4 in Table 5). In short, there is support for Hypothesis 5 in that holiday hunger does appear to at least partially mediate the relationship between economic hardship and parental stress.

Turning to the control variables in Table 6, we see that the number of children and single parents have only a marginal and substantively weak relationship with all types of parental stress (except in Model 7, Table 6 for single parents). We also now see that childcare costs are associated with total parental stress $(2.88,95 \%$ CI 0.27-5.49 [Model 5]), intrusive thoughts $(1.41,95 \%$ CI 0.14-2.68 [Model $6]$ ), and avoidance behavior (1.47, 95\%CI 0.04-2.91 [Model 7]). While these costs have a statistically significant impact on all forms of distress, it is substantively weak. That is, an additional 100 pound per week expenditure on childcare increases total stress by 2.88 points across the sample (Model 5). Given the relatively small standard deviation associated with childcare expenditures it is unlikely that it is a significant source of stress for many parents in this sample.

\section{Discussion and Conclusions}

A growing body of literature has examined the association between food insecurity and mental health [56-64]. We contribute to this literature by examining holiday hunger and parental stress. We do this by measuring holiday hunger using a modified version of the USDA Household Food Security Survey Module and by examining overall levels of stress, intrusive thoughts and avoidance behavior using the Impact of Event Scale that suggests summertime is an impactful event for parents facing 
economic hardship. As far as we are aware, this is one of the few studies to apply the FSM framework to seasonal fluctuations in food insecurity. In particular, we tested five hypotheses consistent with our extension of the FSM framework. Together these five hypotheses have three important implications. First, economic hardship, as measured using unemployment and poverty, is associated with holiday hunger. Being unemployed and residing in a poor household suggests high levels of household food insecurity during the summer months. This finding is consistent with previous qualitative research on holiday hunger in the UK [30] and the family stress model that suggests that economic hardship leads to parental stress [65]. Second, increases in holiday hunger are associated with increases in all types of parental stress. That is, when holiday hunger increases, parental stress, intrusive thoughts and avoidance behaviors also increase. This finding is unique as it extends the study of mental health outcomes to stress and is consistent with the FSM framework. Given the findings in our sample we might ask how parents can effectively engage in important parenting activities if they suffer from severe levels of distress as a result of economic hardship and holiday hunger? This question deserves more investigation. We return to the policy implications associated with this problem below. Third, we find that holiday hunger partially mediates the relationship between household strain and parental stress. That is, unemployment and poverty appear to increase holiday hunger which is related to parental stress. This finding suggests that the political economy matters, and that holiday hunger and parental stress cannot be considered apart from larger economic forces and policies. This finding is also consistent with the FSM model.

Prior to discussing the policy implications of our findings, we suggest that there are a few limitations to our study. First, it is cross-sectional. Future research should explore the impact of holiday hunger on parental stress over time to better test causality. A second drawback of our study relates to the mechanisms of change between holiday hunger and parental summer stress. It may be that this relationship is impacted by dietary intake. That is, we might speculate that micronutrient intake increases psychological outcomes associated with parental stress [66]. The results of such an association are mixed, however [67]. Nevertheless, future research might explore the relationship between dietary deficiencies in parents during the school holidays and how that might impact their mental health outcomes. Third, we are unable to know if our findings are generalizable. In particular, this research relies on a sample of 252 parents obtained by two local authorities in the North East, England. While the sample provided data for a variety of parents, including those who experience all levels of holiday hunger and all levels of summertime stress, it is unknown whether these results would be replicated in other settings. Finally, we suggest that our measure of employment could be improved since it only measures the unemployment status of the parent filling out the survey. In two parent households, the other parent may be employed, which would reduce economic hardship on the household. As a result, the findings for unemployment, while generally supportive of the FSM framework, may not provide a robust test of our theoretical perspective. Future studies of holiday hunger and parental wellbeing should ensure that economic hardship is better reflective of overall household characteristics.

Despite the limited nature of the sample, we suggest that our data are, nevertheless, indicative of a process that is likely to occur in the UK and other advanced capitalist nations where there is some level of limited access to food for school-aged children during the summertime. In the end, if holiday hunger is related to parental stress, this finding would be especially important for policymakers because preventing or ameliorating holiday hunger might reduce the strain on healthcare and social care systems. Moreover, our findings have implications for the complex nature of holiday hunger in the UK. That is, pupils who do not have access to free school meals may not only be food insecure but may suffer from a reduction in the quality of parenting because of parental distress. In particular, if these results are replicated in other settings, governments might consider that potential gains in mental health may be achieved by simply improving children's access to sufficient, safe, and nutritious food. We also suggest that as a wealthy country, the UK can choose to address holiday hunger and food insecurity more generally by implementing policies that improve economic conditions for the most financially 
vulnerable members of society. In this light we suggest that holiday hunger is, above all, a social problem that is facilitated by economic hardships produced by the political economy. Until economic policies are developed to fix this situation the UK and nations like it will continue to see a large portion of the population suffer from holiday hunger and struggle with all its associated outcomes.

Author Contributions: All authors have contributed equally to the manuscript. All authors have read and agreed to the published version of the manuscript.

Funding: This research received no external funding.

Acknowledgments: We would like to thank the anonymous reviewers for their helpful suggestions and acknowledge Gateshead Council and Street Games UK for supporting this research. We are fortunate that our work brings us into contact with such extraordinary people. Any errors in this manuscript are our responsibility.

Conflicts of Interest: The authors declare no conflicts of interest

\section{Appendix A}

Table A1. Correlations, Means \& Standard Deviations.

\begin{tabular}{|c|c|c|c|c|c|c|c|c|c|c|c|}
\hline Variable & 1.00 & 2.00 & 3.00 & 4.00 & 5.00 & 6.00 & 7.00 & 8.00 & 9.00 & 10.00 & 11.00 \\
\hline 1. Total Distress & 1.00 & & & & & & & & & & \\
\hline 2. Intrusion & 0.98 & 1.00 & & & & & & & & & \\
\hline 3. Avoidance & 0.99 & 0.95 & 1.00 & & & & & & & & \\
\hline 4. Holiday Hunger & 0.76 & 0.73 & 0.76 & 1.00 & & & & & & & \\
\hline 5. Unemployed & 0.27 & 0.24 & 0.28 & 0.33 & 1.00 & & & & & & \\
\hline 6. Poverty & 0.54 & 0.52 & 0.55 & 0.43 & 0.18 & 1.00 & & & & & \\
\hline 7. Childcare Expenses & 0.04 & 0.05 & 0.03 & -0.08 & -0.10 & 0.01 & 1.00 & & & & \\
\hline 8. Female & -0.05 & -0.02 & -0.07 & -0.02 & 0.09 & -0.10 & 0.02 & 1.00 & & & \\
\hline 9. No. Children & 0.22 & 0.22 & 0.21 & 0.19 & 0.18 & 0.20 & 0.00 & 0.13 & 1.00 & & \\
\hline 10. Age & -0.25 & -0.25 & -0.24 & -0.23 & -0.15 & -0.25 & 0.08 & -0.07 & 0.04 & 1.00 & \\
\hline 11. Single Parent & 0.43 & 0.40 & 0.45 & 0.45 & 0.24 & 0.26 & -0.07 & 0.02 & 0.02 & -0.26 & 1.00 \\
\hline Mean & 26.92 & 13.54 & 13.38 & 3.75 & 0.66 & 0.46 & 300.00 & 0.84 & 1.91 & 3.69 & 0.45 \\
\hline Standard Deviation & 25.30 & 11.58 & 14.06 & 3.61 & 0.03 & 0.50 & 843.00 & 0.36 & 1.15 & 1.04 & 0.50 \\
\hline
\end{tabular}

\section{References}

1. Foster, D. Holiday hunger should be the shame of this government and it isn't. The Guardian, 25 July 2018. Available online: https://www.theguardian.com/society/2018/jul/25/holiday-hunger-shame-governmentchildrens-clubs (accessed on 14 May 2020).

2. Wall, T. Every day we see really hungry kids. They shouldn't be living like this. The Guardian, 14 August 2019. Available online: https://www.theguardian.com/society/2019/aug/14/uk-holiday-hunger-schemesdeprived-children-summer (accessed on 14 May 2020).

3. Graham, P.; Stretesky, P.; Long, M.; Mann, E.; Defeyter, M. Holiday hunger: Feeding children during the school holidays. In Feeding Children Inside and Outside the Home; Harman, V., Cappellini, B., Faircloth, C., Eds.; Routledge: London, UK, 2019; pp. 87-106.

4. Perraudin, F. Food banks appeal for help to feed children during school holidays. The Guardian, 3 August 2018. Available online: https://www.theguardian.com/society/2018/aug/03/food-banks-appeal-for-help-tofeed-children-during-school-holidays (accessed on 14 May 2020).

5. Blumberg, S.J.; Bialostosky, K.; Hamilton, W.L.; Briefel, R.R. The effectiveness of a short form of the household food security scale. Am. J. Public Health 1999, 89, 1231-1234. [CrossRef] [PubMed]

6. Horowitz, M.J.; Wilner, N.; Alvarez, W. Impact of event scale: A measure of subjective stress. Psychosom. Med. 1979, 41, 209-218. [CrossRef] [PubMed]

7. Conger, R.D.; Conger, K.J. Resilience in midwestern families: Selected findings from the first decade of a prospective, longitudinal study. J. Marriage Fam. 2002, 64, 361-373. [CrossRef]

8. Conger, R.D.; Wallace, L.E.; Sun, Y.; Simons, R.L.; McLoyd, V.C.; Brody, G.H. Economic pressure in African American families: A replication and extension of the family stress model. Dev. Psychol. 2002, 38, 179-193. [CrossRef] [PubMed]

9. Masarik, A.S.; Conger, R.D. Stress and child development: A review of the family stress model. Curr. Opin. Psychol. 2017, 13, 85-90. [CrossRef] 
10. Thompson, M.N.; Dahling, J.J. Employment and poverty: Why work matters in understanding poverty. Am. Psychol. 2019, 74, 673. [CrossRef]

11. Sainsbury, R. Universal credit: The story so far. J. Poverty Soc. Justice 2014, 22, 11-13. [CrossRef]

12. Cheetham, M.; Moffatt, S.; Addison, M.; Wiseman, A. Impact of universal credit in north east England: A qualitative study of claimants and support staff. BMJ Open 2019, 9, e029611. [CrossRef]

13. The Trussell Trust. The Next Stage of Universal Credit: Moving Onto the New Benefit System and Foodbank Use. 2018. Available online: https://www.trusselltrust.org/wp-content/uploads/sites/2/2018/10/The-nextstage-of-Universal-Credit-Report-Final.pdf (accessed on 14 May 2020).

14. Wickham, S.; Bentley, L.; Rose, T.; Whitehead, M.; Taylor-Robinson, D.; Barr, B. Effects on mental health of a UK welfare reform, universal credit: A longitudinal controlled study. Lancet Public Health 2020, 5, e157-e164. [CrossRef]

15. Office of the United Nations High Commissioner for Human Rights. Statement on visit to the United Kingdom, by Professor Philip Alston, United Nations Special Rapporteur on Extreme Poverty and Human Rights; United Nations Human Rights: London, UK, 2018.

16. Richards, J.; Sang, K. Socially irresponsible human resource management? Conceptualising HRM practice and philosophy in relation to in-work poverty in the UK. Int. J. Hum. Res. Manag. 2019, 27, 1-28. [CrossRef]

17. Sanderson, E. Youth transitions to employment: Longitudinal evidence from marginalised young people in England. J. Youth Stud. 2019, 28, 1-20. [CrossRef]

18. Atkinson, A.B. Measuring Poverty Around the World; Princeton University: Princeton, NJ, USA, 2019.

19. Francis-Devine, B.; Booth, L.; McGuinness, F. House of Commons Library Briefing Paper: Number 7096. Available online: https://dera.ioe.ac.uk/34239/1/SN07096\%20\%281\%29.pdf (accessed on 14 May 2020).

20. Dowler, E. Food and poverty in Britain: Rights and responsibilities. Soc. Policy Adm. 2002, 36, e698-e717. [CrossRef]

21. Loopstra, R.; Reeves, A.; Tarasuk, V. The rise of hunger among low-income households: An analysis of the risks of food insecurity between 2004 and 2016 in a population-based study of UK adults. J. Epidemiol. Community Health 2019, 73, 668-673. [CrossRef] [PubMed]

22. Smith, M.D.; Rabbitt, M.P.; Coleman-Jensen, A. Who are the world's food insecure? New evidence from the food and agriculture organization's food insecurity experience scale. World Dev. 2017, 93, 402-412. [CrossRef]

23. United Nations Food and Agriculture Organisation. Rome Declaration on World Food Security and World Food Summit Plan of Action; World Food Summit: Rome, Italy, 1996.

24. United Nations Food and Agriculture Organisation. The State of Food Insecurity in the World 2001; United Nations: Rome, Italy, 2002; pp. 4-7.

25. Gershoff, E.T.; Aber, J.L.; Raver, C.C.; Lennon, M.C. Income is not enough: Incorporating material hardship into models of income associations with parenting and child development. Child Dev. 2019, 78, 70-95. [CrossRef]

26. Gee, K.; Asim, K. Parenting aggravation associated with food insecurity impacts children's behavior and development. Perspectives 2018, 2, 71-77.

27. Huang, J.; Matta-Oshima, K.M.; Kim, Y. Does food insecurity affect parental characteristics and child behavior? Testing mediation effects. Soc. Serv. Rev. 2010, 84, 381-401. [CrossRef]

28. Whitaker, R.C.; Phillips, S.M.; Orzol, S.M. Food insecurity and the risks of depression and anxiety in mothers and behavior problems in their preschool-aged children. Pediatrics 2008, 118, e859-e868. [CrossRef]

29. Melchior, M.; Caspi, A.; Howard, L.M.; Ambler, A.P.; Bolton, H.; Mountain, N.; Moffitt, T.E. Mental health context of food insecurity: A representative cohort of families with young children. Pediatrics 2009, 124, e564-e572. [CrossRef]

30. Stretesky, P.B.; Defeyter, M.A.; Long, M.A.; Sattar, Z.; Crilley, E. Holiday clubs as community organizations. Ann. Am. Acad. Pol. Soc. Sci. 2020. [CrossRef]

31. Gooseman, A.; Defeyter, M.A.; Graham, P.L. Hunger in the primary school setting: Evidence, impacts and solutions according to school staff in the north east of England, UK solutions according to school sta ff in the north east of England, UK. Int. J. Prim. Elem. Early Years Educ. 2019, 3, 1-13.

32. Defeyter, M.A.; Graham, P.L.; Prince, K. A qualitative evaluation of holiday breakfast clubs in the UK: Views of adult attendees, children, and staff. Front. Public Health 2015, 3. [CrossRef] [PubMed] 
33. Stewart, H.; Watson, N.; Campbell, M. The cost of school holidays for children from low income families. Childhood 2018, 25, 516-529. [CrossRef] [PubMed]

34. Long, M.A.; Stretesky, P.B.; Graham, P.L.; Palmer, K.J.; Steinbock, E.; Defeyter, M.A. The impact of holiday clubs on food insecurity-A pilot study. Health Soc. Care Community 2018, 26, e261-e269. [CrossRef]

35. Harvey, K. When I go to bed hungry and sleep, I'm not hungry: Children and parents' experiences of food insecurity. Appetite 2016. [CrossRef]

36. Morgan, K.; Melendez-Torres, G.J.; Bond, A.; Hawkins, J.; Hewitt, G.; Murphy, S.; Moore, G. Socio-economic inequalities in adolescent summer holiday experiences, and mental wellbeing on return to school: Analysis of the school health research network/health behaviour in school-aged children survey in Wales. Int. J. Environ. Res. Public Health 2019, 16, 1107. [CrossRef]

37. Holley, C.E.; Mason, C.; Haycraft, E. Opportunities and challenges arising from holiday clubs tackling children's hunger in the UK: Pilot club leader perspectives. Nutrients 2019, 11, 1237. [CrossRef]

38. McConnon, L.; Morgan, K.; Van Godwin, J.; Hawkins, J.; Bond, A.; Fletcher, A. Food and Fun School Holiday Enrichment Programme 2016; Welsh Local Government Association: Cardiff, UK, 2017.

39. Graham, P.L.; Crilley, E.; Stretesky, P.B.; Long, M.A.; Palmer, K.J.; Steinbock, E.; Defeyter, M.A. School holiday food provision in the UK: A qualitative investigation of needs, benefits, and potential for development. Front. Public Health 2016, 4, 172. [CrossRef]

40. Machin, R.J. Understanding holiday hunger. J. Poverty Soc. Justice 2016, 24, 311-319. [CrossRef]

41. Newkirk, K.; Perry-Jenkins, M.; Sayer, A.G. Division of household and childcare labor and relationship conflict among low-income new parents. Sex Roles 2017, 76, 319-333. [CrossRef]

42. Dean, P.G.; Gow, K.M.; Shakespeare-Finch, J. Counting the cost: Psychological distress in career and auxiliary firefighters. Aus. J. Disaster Trauma Stud. 2003, 1, 1-12.

43. Gill, D.A.; Ritchie, L.A.; Picou, J.S.; Langhinrichsen-Rohling, J.; Long, M.A.; Shenesey, J.W. The exxon and BP oil spills: A comparison of psychosocial impacts. Nat. Hazards 2014, 74, 1911-1932. [CrossRef]

44. Hodgkinson, P.; Joseph, S. Factor analysis of the impact of events scale with female bank staff following an armed raid. Personal. Individ. Differ. 1995, 19, 773-775. [CrossRef]

45. Thompson, V.L. Perceived experiences of racism as stressful life events. Community Ment. Health J. 1996, 32, 223-233. [CrossRef]

46. Yule, W.; Bruggencate, S.T.; Joseph, S. Principal components analysis of the impact of events scale in adolescents who survived a shipping disaster. Personal. Individ. Differ. 1994, 16, 685-691. [CrossRef]

47. Bauer, K.W.; Widome, R.; Himes, J.H.; Smyth, M.; Rock, B.H.; Hannan, P.J.; Story, M. High food insecurity and its correlates among families living on a rural American Indian reservation. Am. J. Public Health 2012, 102, 1346-1352. [CrossRef]

48. Jernigan, V.B.; Huyser, K.R.; Valdes, J.; Simonds, V.W. Food insecurity among American Indians and Alaska natives: A national profile using the current population survey-food security supplement. J. Hunger Environ. Nutr. 2017, 2, 1-10. [CrossRef]

49. Ponnet, K. Financial stress, parent functioning and adolescent problem behavior: An actor-partner interdependence approach to family stress processes in low-, middle-, and high-income families. J. Youth Adolesc. 2014, 43, 1752-1769. [CrossRef]

50. Watkins, D.C.; Pittman, C.T.; Walsh, M.J. The effects of psychological distress, work, and family stressors on child behavior problems. J. Comp. Fam. Stud. 2013, 44, 1-6. [CrossRef]

51. Greene, W. Econometric Analysis; Prentice Hall: Upper Saddle River, NJ, USA, 2008.

52. Baron, R.M.; Kenny, D.A. The moderator-mediator variable distinction in social psychological research: Conceptual, strategic, and statistical considerations. J. Personal. Soc. Psychol. 1986, 51, 1173-1182. [CrossRef]

53. O'Brien, R. A caution regarding rules of thumb for variance inflation factors. Qual. Quant. 2007, 41, 673-690. [CrossRef]

54. Adrian, E.R. Bayesian model selection in social research. Sociol. Methodol. 1995, 25, 111-163.

55. Sterling, M. The impact of event scale (IES). Aust. J. Physiother. 2008, 54, 77-78. [CrossRef]

56. Siefert, K.; Heflin, C.M.; Corcoran, M.E.; Williams, D.R. Food insufficiency and the physical and mental health of low-income women. Women Health 2001, 32, 159-177. [CrossRef]

57. Siefert, K.; Heflin, C.M.; Corcoran, M.E.; Williams, D.R. Food insufficiency and physical and mental health in a longitudinal survey of welfare recipients. J. Health Soc. Behav. 2004, 45, 171-186. [CrossRef] [PubMed] 
58. Hamelin, A.M.; Habicht, J.P.; Beaudry, M. Food insecurity: Consequences for the household and broader social implications. J. Nutr. 1999, 129, 525-528. [CrossRef]

59. Slack, K.S.; Yoo, J. Food hardship and child behavior problems among low-income children. Soc. Serv. Rev. 2005, 79, 511-536. [CrossRef]

60. Maes, K.C.; Hadley, C.; Tesfaye, F.; Shifferaw, S. Food insecurity and mental health: Surprising trends among community health volunteers in Addis Ababa, Ethiopia during the 2008 food crisis. Soc. Sci. Med. 2010, 70, 1450-1457. [CrossRef]

61. Weaver, L.J.; Hadley, C. Moving beyond hunger and nutrition: A systematic review of the evidence linking food insecurity and mental health in developing countries. Ecol. Food Nutr. 2009, 48, 263-284. [CrossRef]

62. Cole, S.M.; Tembo, G. The effect of food insecurity on mental health: Panel evidence from rural Zambia. Soc. Sci. Med. 2011, 73, 1071-1079. [CrossRef]

63. Maynard, M.; Andrade, L.; Packull-McCormick, S.; Perlman, C.M.; Leos-Toro, C.; Kirkpatrick, S.I. Food insecurity and mental health among females in high-income countries. Int. J. Environ. Res. Public Health 2018, 15, 1424. [CrossRef] [PubMed]

64. McLaughlin, K.A.; Green, J.G.; Alegria, M.; Costello, E.J.; Gruber, M.J.; Sampson, N.A.; Kessler, R.C. Food insecurity and mental disorders in a national sample of US adolescents. J. Am. Acad. Child Adolesc. Psychiatry 2012, 51, 1293-1303. [CrossRef]

65. Lohman, B.J.; Stewart, S.; Gundersen, C.; Garasky, S.; Eisenmann, J.C. Adolescent overweight and obesity: Links to food insecurity and individual, maternal, and family stressors. J. Adolesc. Health 2009, 45, 230-237. [CrossRef] [PubMed]

66. Kaplan, B.J.; Crawford, S.G.; Field, C.J.; Simpson, J.S. Vitamins, minerals, and mood. Psychol. Bull. 2007, 133, 747. [CrossRef] [PubMed]

67. Tiemeier, H.; Hofman, A.; Kiliaan, A.J.; Meijer, J.; Breteler, M.M. Vitamin E and depressive symptoms are not related. J. Affect. Disord. 2002, 72, 79-83. [CrossRef]

(C) 2020 by the authors. Licensee MDPI, Basel, Switzerland. This article is an open access article distributed under the terms and conditions of the Creative Commons Attribution (CC BY) license (http://creativecommons.org/licenses/by/4.0/). 